\title{
USING SIMPLE SEMI-EMPIRICAL MODELS FOR INTEGRATED ASSESSMENT OF SCENARIOS FOR A NAVIGATION CHANNEL. THE CASE OF THE PORT OF OSTEND, BELGIUM.
}

\author{
Toon Verwaest ${ }^{1}$
}

1. Flanders Hydraulics Research, Berchemlei 115, B-2140 Antwerp, Belgium, toon.verwaest@mow.vlaanderen.be

Abstract: Scenarios for a new navigation channel to the port of Ostend (Belgium) are to be assessed. Regarding coastal sediments dynamics, two aspects are of importance: first the maintenance dredging of the navigation channel itself (functional aspect), secondly the impact on the surrounding environment. The latter involves primarely the impact on the morphology of the sea bottom and the impact on the turbidity of the coastal waters. Available results of in situ-measurements, numerical modeling and laboratory experiments for the Belgian coastal zone were gathered, as well as general scientific literature. It could be concluded that the state of knowledge on coastal sediment dynamics in the Belgian coastal zone is to limited to be able to completely validate a process-based numerical model. A simple semi-empirical model was built, that is able to represent the essence of the impact on coastal sediment dynamics of a new navigation channel.

\section{INTRODUCTION}

The assessment of master plans of coastal ports comprises an assessment of the impact of scenarios regarding coastal sediment dynamics. A functional assessment as well as an environmental assessment are needed. Recent European legislation on environmental impact assessment (EIA) stipulates the use of a cascade approach in two steps : first an assessment of scenarios of masterplans (a strategic EIA) and secondly a more detailed assessment of scenarios of infrastructure works that implement a chosen master plan (a project EIA). This regulation -adding the concept of a strategic EIA- aims at considerations of environmental impact already to be taken into account in the earliest stages of design. 
Thuss, for master plan studies a multidisciplinary approach has to be followed. Integration of the different disciplines is very important. Using simple semi-empirical models that can be easily understood by non-experts, but still are able to represent the essence of the impact on coastal sediment dynamics are very usefull in such a framework.

\section{THE CASE OF IMPROVING THE NAVIGATION CHANNEL TO THE PORT OF OSTEND, BELGIUM}

For the accessibility of larger ships to the port of Ostend an improved navigation channel is needed, amongst other infrastructure works (e.g. larger breakwaters). The port of Ostend is situated at the Belgian coastline in the southern part of the North Sea. Scenarios for an improved navigation channel have to be assessed, taking into account not only the accessibility for the largest ships but also other functional and environmental issues. Regarding impact on coastal sediments dynamics, two aspects are of importance: first the impact on maintenance dredging of the navigation channel itself (functional aspect), secondly the impact on the surrounding environment. The latter involves primarely the impact on the morphology of the sea bottom (erosion due to dredging nearby) and the impact on the turbidity of the coastal waters. To assess these impacts a.o. a semi-empirical model was elaborated taking into consideration all the available expertise on coastal sediment dynamics in the area that is relevant for the assessment of improved navigation channel scenarios.

\section{STATE OF KNOWLEDGE ON COASTAL SEDIMENT DYNAMICS IN THE AREA}

The sea bottom morphology is characterised by the presence of shore parallel sandbanks and swales. This is illustrated on Figure 1. On this figure the present navigation channel and the most probable future navigation channel are indicated.

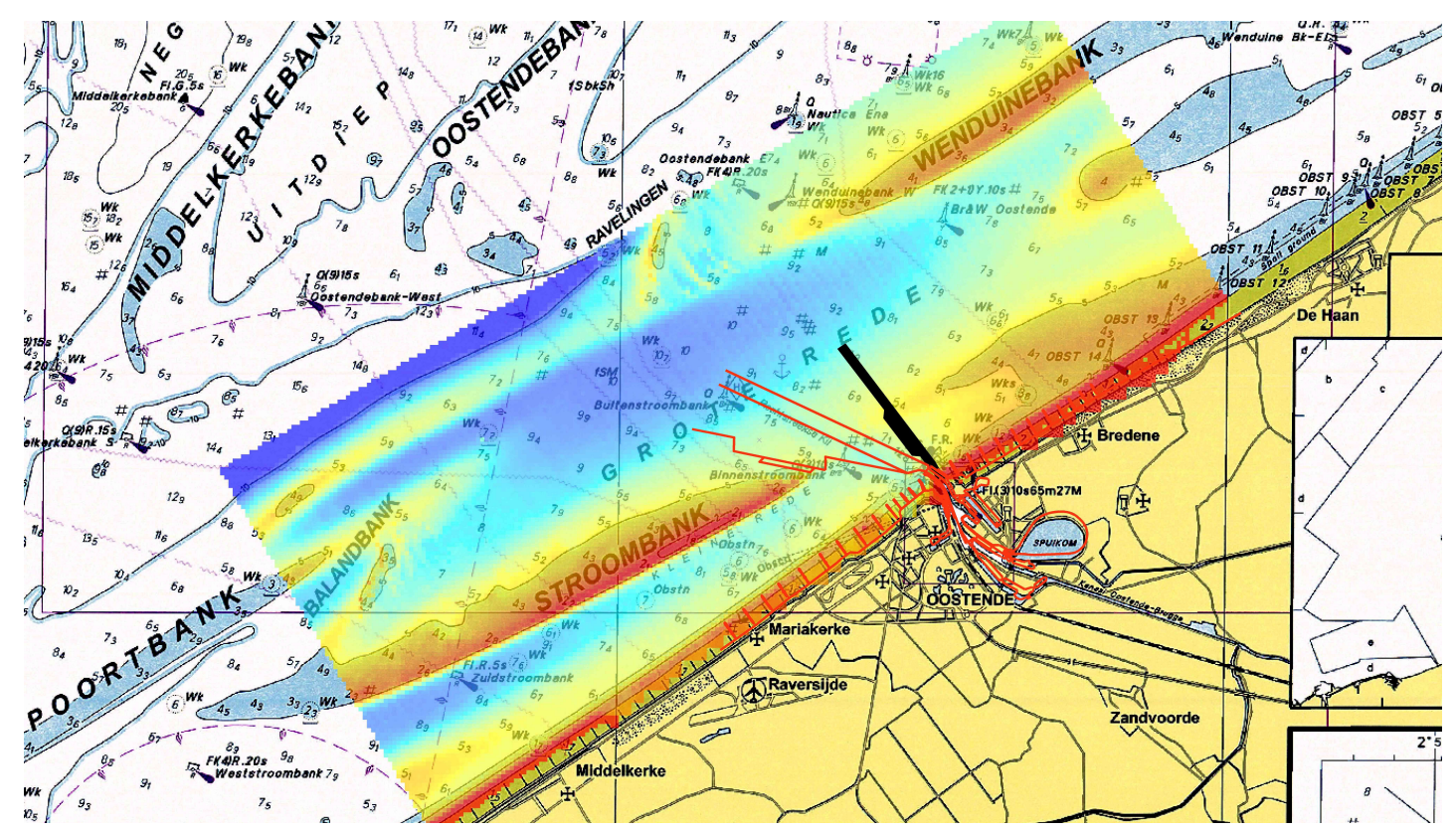


Fig. 1. Sea bottom in front of Ostende, with indication of the most probable future navigation channel (in black) and the present navigation channel (in red)

The sea bottom sediments in the area of the new navigation channel are a mixture of sand and mud particles. From in situ measurements -although limited in number- the relative mass percentages are determined as $50 \%$ sand particles $(>63 \mu)$ and $50 \%$ mud particles $(<63 \mu)$. This composition is based on measurements of surfacial sediment samples. Only a few analyses of drillings are available. Thin layers of soft mud are found in patches on the sea bottom, especially in the lower lying areas after calm weather and neap tides. Waves or spring tide currents remobilises this soft mud.

Prevailing residual tides, winds as well as waves all result on a yearly basis in a net transport from SW to NE. From operational hydrodynamic models, which have been calibrated and validated through many years of oceanographic research around the Belgian Continental Shelf, it follows that a water particle takes on average ca. 4 weeks to cross the Belgian coastal waters (65 km in length, from SW to NE).

The dynamics of mud particles and sand particles are very different. Their dynamics is treated separately, assuming no interaction of mud and sand. Process based models for mud transport as well as sand transport in the Belgian coastal zone are still work in progress. Several decades of research have not yet resulted in completely validated models, indicating the complexity of the coastal sediment dynamics.

\section{Mud dynamics}

Regarding mud dynamics the state of knowledge on the large scale is described in Fettweis et al (2005). The major natural transport of mud in the area is a yearly net transport of ca. 15 M TDS (Million Ton Dry Solids) mud per year through the Dover Strait and continuing along the coastline of Belgium (from SW to NE). Mud is advected with the residual water flow. The major antropogene mud transport is by maintenance dredging of the navigation channels and coastal ports in Belgian coastal waters. It amounts to ca. $10 \mathrm{M}$ TDS mud per year. All dredged mud is also dumped in Belgian coastal waters. From several years of remote sensing observations (satelite SeaWIFFS, MODIS Aqua and MODIS images) as well as in situ profile measurements the concentration of mud in suspension is determined as ca. $50 \mathrm{mg} / \mathrm{l}$ on average for the more shallow coastal waters (from the coastline to ca. $25 \mathrm{~km}$ out the coastline). The resulting amount of mud in suspension is calculated as ca. 2 M TDS mud. The mud on the sea bottom which is readily available for transport, it is the patches of thin layers of mobile soft mud, is roughly estimated to be ca. 20 M TDS on average -although not enough measurements are available for a reliable estimate. The yearly erosion of consolidated mud (in areas where clayey soil outcrops) and the yearly sedimentation+consolidation of mud (in some sheltered areas) are of the magnitude of a few M TDS mud per year, and are more or less compensating each other.

\section{Sand dynamics}

Regarding sand dynamics the state of knowledge on the large scale is described in Van Lancker et al (2005). Large scale sand dynamics in the area is determined by a yearly net 
alongshore transport in the direction of the prevailing currents and waves (from SW to $\mathrm{NE}$ ). However, this net sand transport is the result of alternating gross sand transport intensities that are an order of magnitude (factor 10) larger. The momentous sand transport alternates mainly between SW to NE and NE to SW (parallel to the coastline), in accordance with the alternating current direction. The current climate and the wave climate are known accurately, but the resulting net sand transport cannot be determined accurately from this hydrometeo climate because there is no completely validated sediment transport formula available.

From historical nautical maps the morphological response to a navigation channel across the sandbanks can be observed. In the beginning of the $20^{\text {th }}$ century for the first time a navigation channel across the shore-parallel sandbank "Oostendebank" was dredged. During the $20^{\text {th }}$ century this navigation channel, called "Rechtstreekse Kil", has been deepened progressively as the draft of the ships in use became larger and larger. The morphological response caused by the creation, maintenance and deepening of this navigation channel appears to extend much further than the location of the dredging works itself. Relatively accurate historical nautical maps are available every ca. 5 years for this area for the period from the mid $20^{\text {th }}$ century until present. From this time series the area where the influence of the navigation channel is dominant is determined. This influence area is ca. $10 \mathrm{~km}^{2}$, for a navigation channel of less than $1 \mathrm{~km}^{2}$. This influence area corresponds to the establishment of a morphological equilibrium slope of ca. 1/200. A clear correlation between the depth of the navigation channel and the sediment volume in the influence area is determined. This correlation is shown in Figure 3.

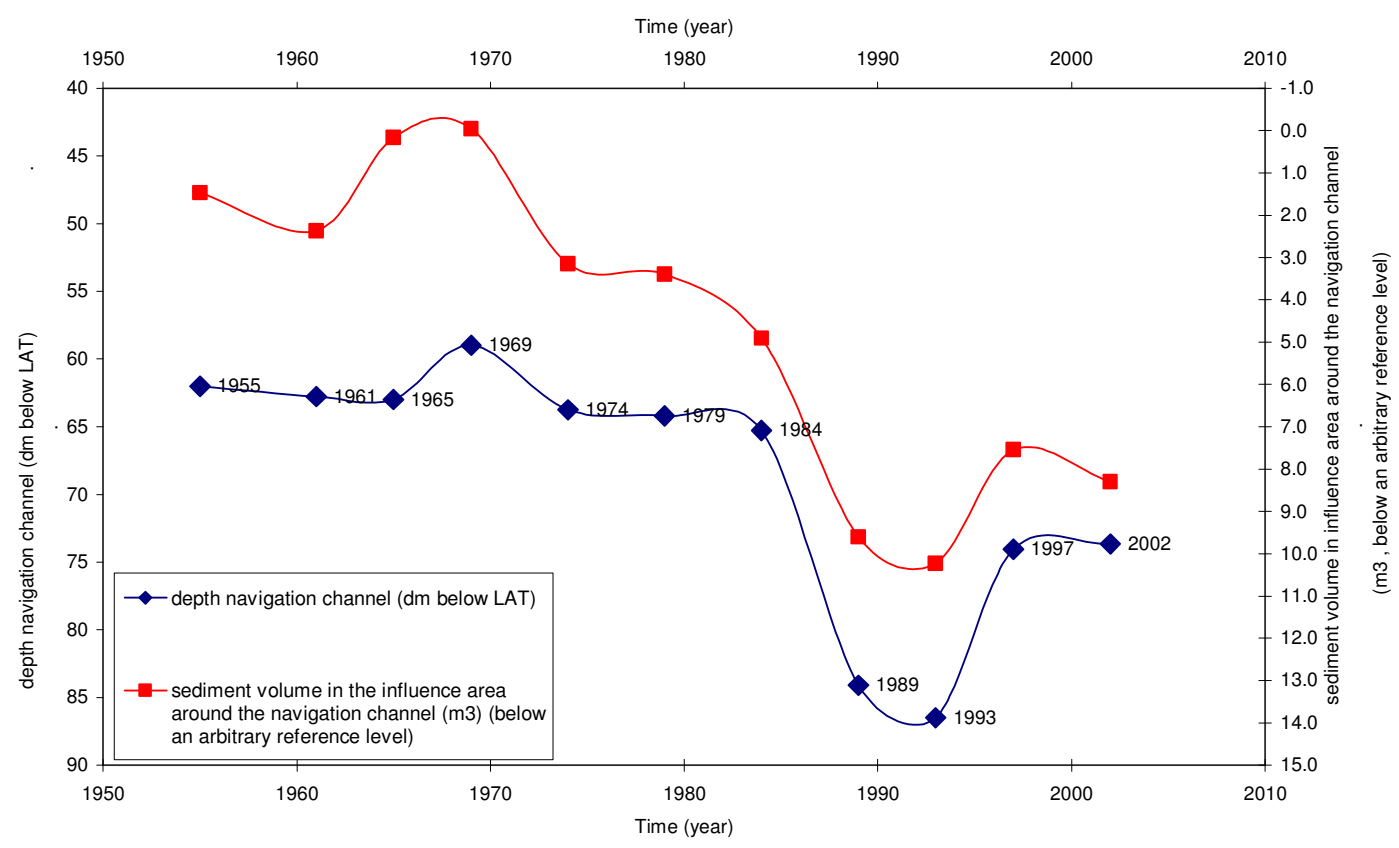

Fig. 3. Correlation between the depth of the navigation channel and the sediment volume in the influence area around the navigation channel 


\section{SEMI-EMPIRICAL MODELS FOR MUD AND SAND DYNAMICS}

The state of knowledge is incorporated in these semi-empirical models.

\section{Mud dynamics}

A distinction is made between an equilibrium, steady state and a state of transition (between successive equilibrium states). The equilibrium state for mud is described in Figure 4.

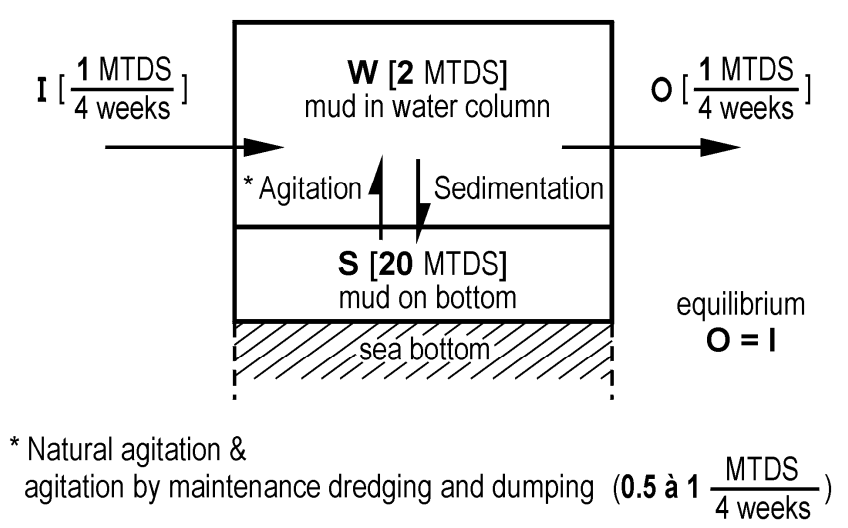

Fig. 4. Concept of equilibrium mud dynamics in the Belgian coastal waters

If one of the boundary conditions changes then the equilibrium state changes. For example, when due to the dredging of an improved navigation channel an additional, permanent source of mud sediment is created, after some time the amounts of mud in the water column, on the bottom and transported per time unit out of Belgian coastal waters will be increased correspondingly. Following a linear approximation the new equilibrium state is then described by the Figure 5 .

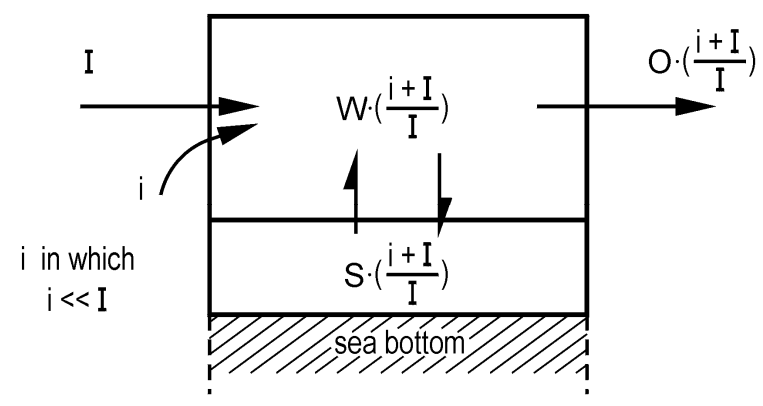

Fig. 5. Effect of an additional, permanent source of mud on the equilibrium steady state

where $W=$ amount of mud in the water column (M TDS); $S=$ amount of mud on the bottom (M TDS); $I=$ transport of mud into Belgian coastal waters (M TDS / 4 weeks); $O$ $=$ transport of mud out of Belgian coastal waters (M TDS / 4 weeks); $i=$ additional source of mud into Belgian coastal waters (M TDS / 4 weeks); 
It is convenient to define $r$ as the ratio of the additional source of mud relative to the major transport into Belgian coastal waters (Eq. 1).

$$
r=\frac{i}{I} \quad \text { with } r<<1
$$

The basic assumption is to consider a linear system with two system constants, $\alpha$ and $\gamma($ Eq. 2).

$$
\alpha=\frac{W}{S} \quad ; \quad \gamma=\frac{W}{O}
$$

The system constant $\alpha$ is describes the equilibrium between the processes of agitation, natural as well as antropogene, and the processes of sedimentation. The system constant $\gamma$ is the average resident time in Belgian coastal waters of a mud particle that (by chance) never reaches the bottom.

From conservation of mass for mud and substution of Eq. 2 (Eq. 3) it follows that the transition from one equilibrium state to a new equilibrium state is then described by an exponential decay curve with a half time $\tau$ given by Eq. 4 (integration of Eq.3).

$$
\begin{gathered}
\frac{d W}{d t}+\frac{d S}{d t}=\frac{d W}{d t}+\frac{d W}{d t} \frac{1}{\alpha}=I+i-O=I+i-W \frac{1}{\gamma} \\
\tau=\gamma\left(1+\frac{1}{\alpha}\right) \ln (2)
\end{gathered}
$$

where $\tau=$ the time it takes to reach the mean state between two successive equilibrium states. The transition from the initial equilibrium state (with $i=0$ ) to a new equilibrium state (with $\mathrm{i}=\mathrm{i}$ ) is mathematically described by Eq. 5 .

$$
W(t)=W_{1}+\left(W_{2}-W_{1}\right)\left(1-\exp \left(-\frac{t}{\tau}\right)\right)
$$

where $W_{1}=$ amount of mud in the water column for the initial equilibrium state (M TDS); $W_{2}=$ amount of mud in the water column for the new equilibrium state (M TDS); 


\section{Sand dynamics}

The semi-empirical model for sand states that the sedimentation of sand in a navigation channel is the sum of two processes. First there is sedimentation of a fraction of the sand which is transported along the Belgian coastline. Second there is sedimentation of the sand which is eroded in the "upstream" part of the influence area of the navigation channel. "Upstream" signifies SW from the navigation channel given the net sand transport from SW to NE. The sand which is eroded in the "downstream" part of the influence area is transported away from the navigation channel. This semi-empirical model is schematically described in Figure 6.

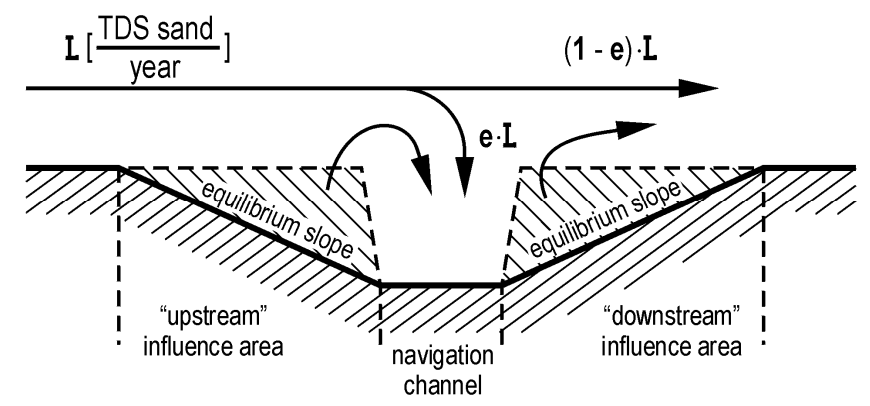

Fig. 6. Concept of sand dynamics in and around a navigation channel

where $e=$ the trapping efficiency factor $(-) ; \mathrm{L}=$ the net sand transport along the Belgian coastline (M TDS / year).

The basic assumption is to consider no interaction between both processes for sedimentation of sand in the navigation channel (Eq. 6).

$$
Q_{\text {sum }}=Q_{1}+Q_{2}
$$

where $Q_{\text {sum }}=$ the sedimentation rate of sand in the navigation channel (M TDS / year); $Q_{l}=$ the sedimentation rate of sand transported along the Belgian coastline (M TDS / year); $Q_{1}=$ the sedimentation rate of sand that is being eroded in the influence area around the navigation channel, which is caused by the dredging of the naivigation channel itself (M TDS / year).

The first contribution $Q_{1}$ is calculated as (Eq. 6)

$$
Q_{1}=e L
$$

in which the trapping efficiency factor $e$ is calculated using the engineering approach given in Van Rijn (2005) which is introduced in Van Rijn (1987).

The second contribution $Q_{2}$ is calculated as (Eq. 7) 


$$
Q_{2}=E
$$

in which $E$ is the erosion rate of the upstream influence area (M TDS/year).

\section{APPLICATION RESULTS}

The described semi-empirical models are applied for different scenarios of improved navigation channels to the port of Ostend. For each scenario this results in a projection of the evolution of the necessary yearly maintenance dredging works -separately for sand and mud-, and in projections of the evolution of the increased turbidity and the extent of the erosion zone surrounding the navigation channel.

The results for one of the scenarios are given here after. Details can be found in Verwaest (2005). However, because the study is still ongoing no quantitative results are given in this paper.

The projection of the evolution of the maintenance dredging works is given in Figure 7. One can note that during the first ca. 3 years after the capital dredging works important quantities of sedimentation are to be expected, which are caused by the erosion in the influence area around the navigation channel where there is a gradual process of slopes flattening towards the equilibrium morphological slope.

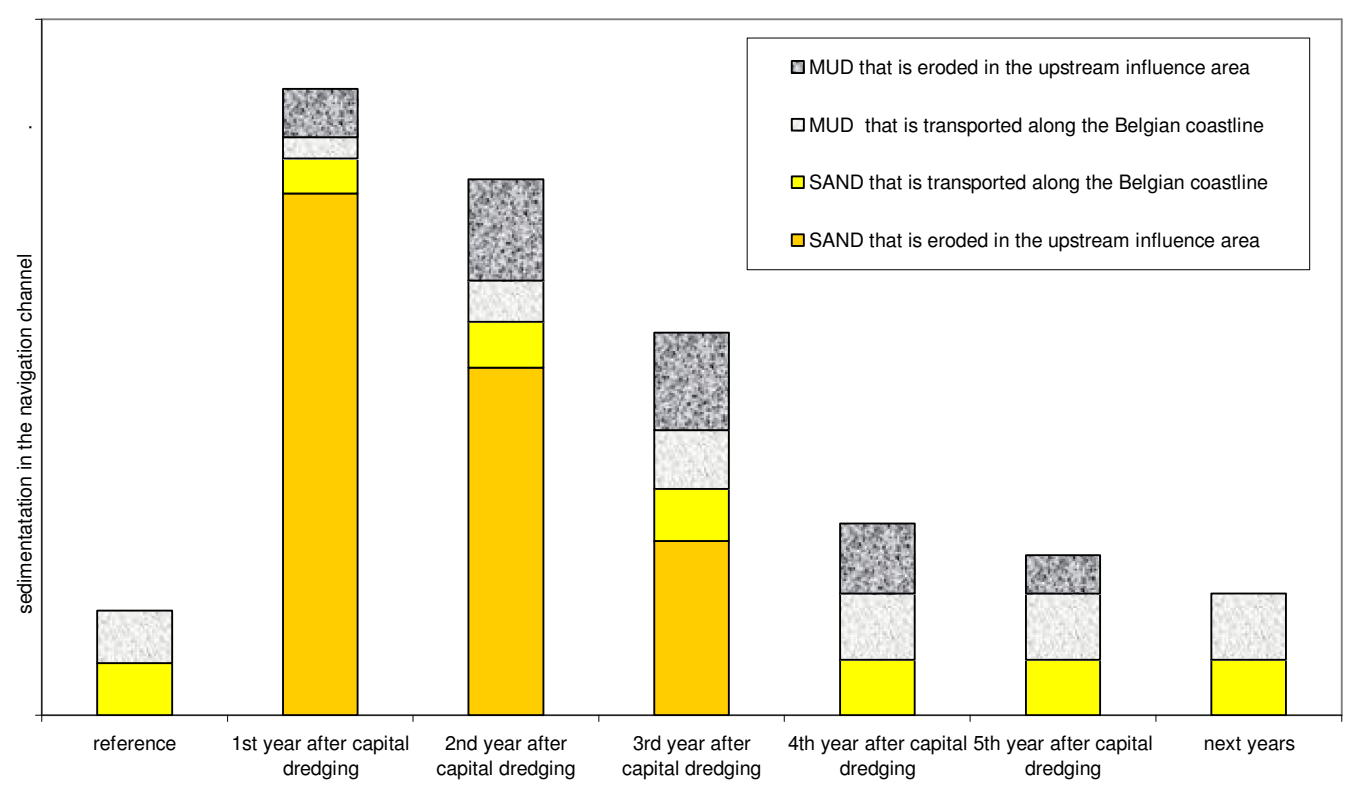

Fig. 7. Necessary maintenance dredging works after the capital dredging for a scenario of a new navigation channel to the port of Ostend. 
Projections for increased turbidity in Belgian coastal waters are shown in Figure 8. A maximum increase after ca. 3 years and a half time $\tau$ equal to ca. 61 weeks can be seen.

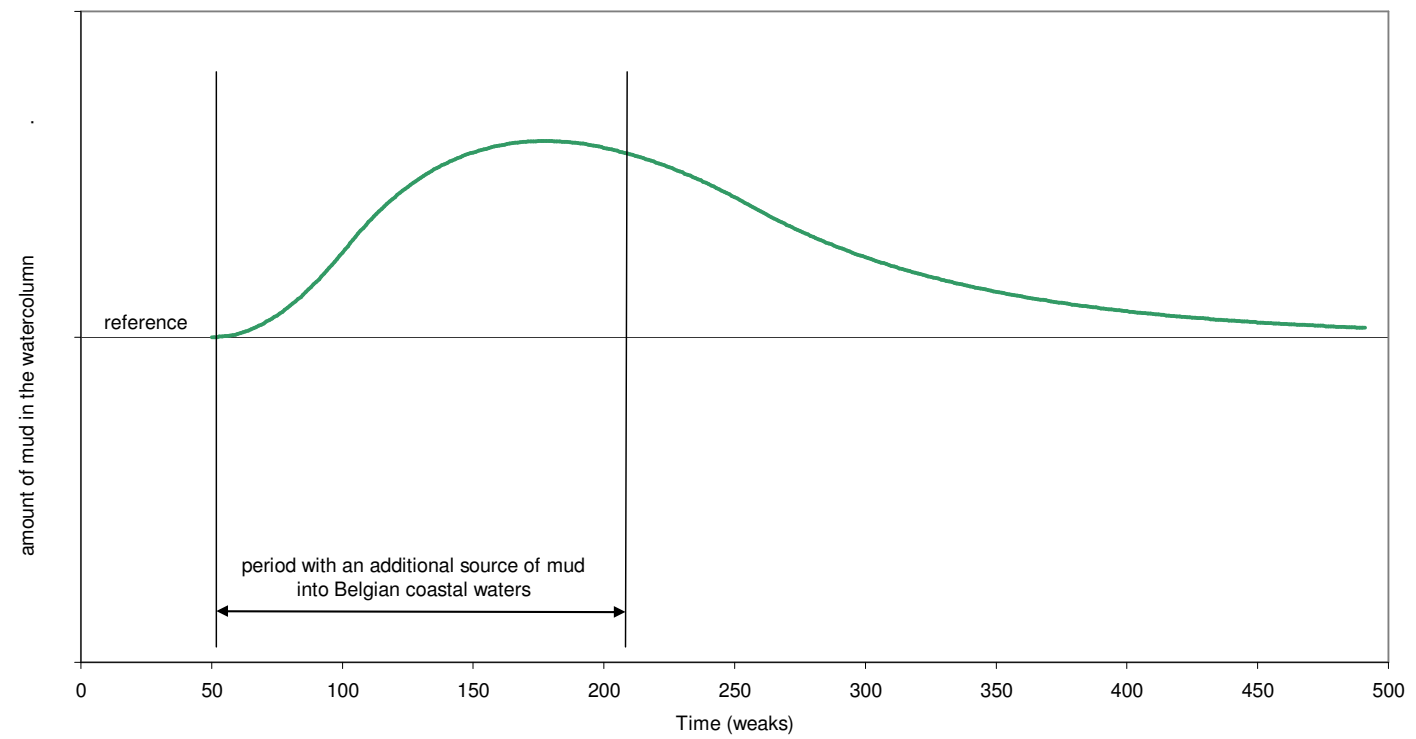

Fig. 8. Impact on turbidity in Belgian coastal waters of an additional source of mud of ca. 1,5 $M$ TDS which is released during a period of 3 years (with a decreasing rate).

Projections of the extent of the erosion zone around the new navigation channel are made in a GIS. Using an average equilibrium slope of ca. 1/200 it is shown that an erosion zone of ca. $5 \mathrm{~km}^{2}$ is affected, with the surface area of the navigation channel itself only ca. $0,5 \mathrm{~km}^{2}$.

\section{CONCLUSION}

A simple semi-empirical model was built that is able to represent the essence of the impact on coastal sediment dynamics of a new navigation channel in the Belgian coastal zone. The model treats mud dynamics and sand dynamics separately. Using this model projections for maintenance dredging, erosion, and turbidity increase are successfully made for scenarios of a new navigation channel to the port of Ostend.

\section{REFERENCES}

Fettweis M., Francken F., Van den Eynde D., Houziaux J.-S., Vandenbergh N., Fontaine

K., Deleu S., Van Lancker V., Van Rooij D, (2005). "Mud origin, characterization and human activities (MOCHA): Characteristics of cohesive sediments on the Belgian Continental Shelf”, Scientific Report Year 1, Belgian Science Policy, 70 p. Van Lancker V., Deleu S., Bellec V., Du Four I., Verfaillie E., Fettweis M., Van den Eynde D., Francken F., Monballiu J., Guardino A., Portilla J., Lanckneus J., Moerkerke G. \& Degraer S. (2005). "Management, research and budgeting of aggregates in shelf seas related to end-users (Marebasse)", Scientific Report Year 3. 
Belgian Science Policy, 103 p.

Van Rijn L. (1987). "Mathematical modeling of morphological processes in the case of suspended sediment transport”, $\mathrm{PhD}$ thesis, Delft University of Technology, the Netherlands.

Van Rijn L. (2005). "Principles of sedimentation and erosion engineering in rivers, estuaries and coastal seas”, Aqua Publications.

Verwaest T. (2005). "Haven van Oostende - verbeterde haventoegang - impact op de baggerwerken”, Tech. Rep. MOD 627/6, Flanders Hydraulics Research, Antwerpen, Belgium. 